\title{
¿QUÉ «YO» ES VALIOSO PARA EL MUNDO DE HOY?
}

\author{
What "I" is valuable for the actual world?
}

\section{Quel "je" est valide pour le monde actuel?}

José Ángel López Herrerías

Universidad Complutense de Madrid. Facultad de Educación. Departamento de

Teoría e Historia de la Educación. C/ Rector Royo Villanova, s/n. 28040 Madrid.

Correo-e: jherrer@edu.ucm.es

Fecha de recepción: enero de 2010

Fecha de aceptación definitiva: abril de 2010

Biblid [(1130-3743) 22, 1-2010, 65-90]

\section{RESUMEN}

Las propuestas de renovación pedagógica están motivadas por la conciencia de vivir un mundo problemático. Es frecuente el interés social y académico referido a cómo actuar bien en un mundo multicultural, exigido de desarrollo sostenible, y en el que la experiencia de los derechos humanos impida el incremento del analfabetismo, el hambre, la pobreza y la injusticia, además de promover más acciones de dignidad y de libertad. Desde la Pedagogía, las respuestas se afanan en promover renovaciones metodológicas (educación popular, animación sociocultural, desarrollo comunitario), que puedan educarnos para ser capaces de superar esos retos. El problema central reside en clarificar qué sujeto, qué actor narrativo, ponemos en el escenario del teatro de la convivencia que realice las metodologías referidas, y que, sobre todo, alcance la "renovación ética" necesaria. El ser humano metamoderno: un yo más ético que cognitivo.

Palabras clave: retos socioculturales, derechos humanos, Teoría de la Educación, renovación pedagógica, ética de la educación, el yo/sujeto de la educación. 


\section{SUMMARY}

The proposals for the pedagogical renewal are motivated by the awareness of living in a problematic world. The social and academic interest is frequent in relation to how to act-behave well in a multicultural world, demanding soustainable development. In such a world, the advancement of human rights impedes the increase in illiteracy, hunger, poverty and injustice, in addition to promoting more dignity and freedom. From the viewpoint of Pedagogy one has to try hard to promote methodological renewals (popular education, socio-cultural animation, community development), which can educate us in order to be capable overcome these challenges. The main problem resides in the clarification of what type of individual, and what type of narrative actor should be placed in the theatre of living together that would carry out the mentioned methodologies, and above all, to achieve the required ethics of renewal. This should render the "metamodern" human being more ethical than cognitive.

Key words: socio-cultural challenges, human rights, Theory of Education, pedagogical renovation, ethics of education, ego/subject of education.

\section{SOMMAIRE}

Les propositions pour un renouveau pedagogique sont motivées par la conscience de vivre un monde problématique. Il est frequent l'intêret social et académique raconté avec actuer bien dans un monde multiculturel, exigé de déroulement soutenu, et dans lequel l'experience des droits humains empêche l'acroissement de l'analphabetisme, la faim, la pauvreté et l'injustice, en outre de promouvoir plus actions de dignité et de liberté. Depuis la Pedagogie, les reponses essayent promouvoir renouveaux méthodologiques (éducation populaire, animation socioculturelle, deroulement communautaire), que nous peuvent éduquer pour être capables de depasser ces defis. Le problème central est en clarifier quel sujet, quel acteur narrative, nous mettrons dans le scène du théâtre de la coexistence, que réalise les méthodologies citées, et que, sur tout, atteint la "renouveau éthique" necessaire. L'être humain metamoderne: un "je" plus éthique que cognitive.

Mots clés: defis socio-culturels, droits humains, Théorie de l'Éducation, renouveau pedagogique, éthique de l'éducation, moi/sujet de l'éducation.

\section{Clarificación CONCEPTUAL y ARgUMental}

En función del mundo que hoy se nos presenta construido, con sus narraciones y sus libretos, la forma de pensar y de actuar no puede seguir los dominantes estilos de la tradición establecida. No podemos seguir anclados en la secuencia sintagmática - presencia aceptada de signos relacionados- con los mismos estilos de pensamiento y de acción que los paradigmas dominantes 
-los códigos vigentes- nos dictan. Decididamente, hay que descubrir y enseñar nuevos horizontes y ponernos en el borde de lo establecido. Esto es, generar otras propuestas de fines/valores y de medios/actos educativos, que nos acerquen a otro tipo de conductas más adecuadas y convenientes para los retos que conocemos y que nos abordan ineludiblemente. Es necesario enfrentarse a un nuevo y decidido giro copernicano. El giro copernicano más antropológico de los considerables en el realizarse de la conciencia europea/occidental.

Si el primer y nombrado así "giro copernicano" (Nicolás Copérnico) fue el que nos hizo ver que la Tierra no era el centro del universo, otros eventos posteriores pueden denominarse metafóricamente de semejante manera, dado el fuerte impacto de cambio y de renovación que los nuevos movimientos comportaban. Así, la Revolución Francesa (1789) -cenit de un largo tiempo de lucha, y expresión de una nueva racionalidad- puede denominarse giro copernicano sociopolítico. Libertad, igualdad y fraternidad eran los goznes de una nueva visión de la convivencia social y política. Se abandonaba la consideración de los grupos humanos diferenciados, jerarquizados y, de alguna manera, clasificados en rangos, verticalidad -estamentos-, y se pasaba a una perspectiva de horizontalidad en la que todos y cada uno de los seres humanos se consideraba igual a todo otro. Así, la Declaración de los Derechos del Hombre y del Ciudadano (26/8/1789), artículo primero, dice: "Los hombres nacen y viven libres e iguales en derechos. Las distinciones sociales no pueden fundamentarse sino sobre la utilidad común". Lo que se trastocaba en este giro no era tanto el conocimiento de lo físico, sino la forma de entender y realizar la vida sociocultural, centrada en la cuestión política. ¿De quién es el poder?, ¿quién lo ejerce?, ¿cómo se puede ejercer? El ser humano, los pueblos, al menos en Occidente, pasan a ser los sujetos de la historia, dado que todos somos libres, iguales y fraternos. Se acababan oficialmente los tiempos de los estados, inamovibles e impermeables entre sí, en los cuales los proletarios, las mujeres, los niños... prácticamente no tenían el estatuto de ser humano pleno. Lo había sido la realeza, la nobleza, en ese momento revolucionario la burguesía, y aparecía, por primera vez, el intento de estar presente del proletariado (cuarto estado), el común de las gentes, los no propietarios. Gran cambio (un "segundo giro copernicano"), que está en el germen de casi todos los logros más actuales de nuestra sociocultura, aún muy por madurar y desarrollar en mayor plenitud y extensión.

En este actual "tiempo eje" (Jaspers, 1976, 23) del cambio de siglo y de milenio, de las exigencias de generar una nueva conciencia y de los retos y los problemas radicalmente provocadores, por nuevos y comprometidos, se hace necesario el paso a un nuevo y tercer giro copernicano. Un giro definible como antropológico, dado que la realidad en la que se centra es la consideración directa del propio ser humano: que deje de ser considerado como substancia aislada, preparada por la naturaleza y desde sí misma, para poder y dominar a los demás. Pasar de la ley del más fuerte, capaz de tomar medidas respecto de los otros y del conjunto de la realidad, a reconocerse sólo y radicalmente desde la incidencia y presencia de y con los otros, realidad humana ineludiblemente comunitaria. Esa realidad comunitaria, 
tercer giro copernicano, que aquí se plantea, es lo que nos exige el hecho de encontrarnos y entendernos, de forma ineludible, interrelacionados. Ni individualismo, ni colectivismo (Buber, 1969). También conocedores de que todas y cada una de las experiencias que vivimos son compartidas y además influyentes en todos y cada uno de los otros. Sólo nos falta convencernos cognitiva y emocionalmente de que nuestro mundo humano en la Madre Tierra no tiene otra oportunidad de salida que decidirnos por llevar a la acción otro estilo de convivencia. La historia de la vida nos reclama que seamos capaces de vivir como nuevos actores lo que ya hemos aprendido. Pero, eso sí, aprendido de forma incompleta e irreflexiva y, desde luego, sin emoción, casi como si fuese tema de mero y superficial aprendizaje para examinarse y no para vivirlo. El asunto no aguanta ni más dilaciones, ni más hipocresía, ni más cruentos ni espeluznantes errores. Sabemos que todos y cada uno somos lo que somos por y desde la radical interdependencia de surgir a ser humano todos de entre todos. Que la imagen lingüística del yo, pronombre sustantivo de primera persona, nos impide reconocernos como una realidad radicalmente interdependiente y hermanada. Aprender que ese yo, más que una sustancia aislada y autosuficiente, es una cristalización de responsable libertad, emergida desde el inagotable nudo de encuentros entre todos los otros. El yo dialécticamente emergido del ineludible magma de humanidad que es el nos-otros. Sabemos que el mundo es limitado. Que no podemos producir, ni consumir, para acumular, como única meta de la existencia. Este asunto "copernicano" referido al sujeto humano, que vive y se educa, es uno de los interrogantes más relevantes de la Teoría de la Educación. Investigar cómo reconocer y definir el yo que ha de percibirse y proyectarse en las exigidas innovaciones pedagógicas que nos reclama el mundo actual.

El complejo discurso pedagógico exige la clarificación de los conceptos y los argumentos relacionados con aquello de lo que se trata. Así, podemos distinguir:

a) El ámbito de la realidad sociocultural desde el que se reta el mundo actitudinal vivido y los hábitos desarrollados: hoy nuestro campo de convivencia sociocultural está marcado por las exigencias ecológicas, interculturales y cooperativas de la convivencia globalizada. En resumen, se trata de comprender la actual confluencia de dos tipos complementarios de fenómenos que se nos presentan hoy como un central desafío cultural y ético, o sea educativo. De un lado, hemos incrementado, no sé si al nivel que requieren los retos y los problemas de la experiencia, la conciencia de responsabilidad de aquello que hacemos ocurrir en el tapete de la historia. Así, tras la II Guerra Mundial, la Declaración Universal de los Derechos Humanos del 10 de diciembre de 1948 es un hito de humanización que siempre podemos ponderar en todo lo que vale y puede llegar a valer. Eso, en la medida en que dicha Declaración sea un proyecto que se concreta progresivamente cada vez más en su realización. 
El artículo 1 es un magnífico marco de referencia que bien sintetiza ese sentido proyectivo de valor: "Todos los seres humanos nacen libres e iguales en dignidad y derechos y, dotados como están de razón y conciencia, deben comportarse fraternalmente los unos con los otros". Libertad, igualdad, dignidad y fraternidad. Desde entonces, y a la luz de las exigencias de esa Declaración, se han incrementado a lo largo y ancho del mundo organizaciones, grupos internacionales, grupos de análisis y de responsabilidad, que intentan ser voces permanentes, en la llamada de atención, de ese proyectado y anunciado mundo.

Además, de otro lado, el añadido y actual fenómeno diferenciador, para percibir el incremento de conciencia colectiva de los desajustes y los desafíos del mundo, hace referencia a la "global comunicación" en la que hoy sabemos cómo se vive en todos los lugares del Planeta. No hay ya lugar para la mentira, la mirada hacia otro lado, o la inhibición ante los gritos de hambre, pobreza, destrucción, violencia, analfabetismo, que unos provocamos sobre los otros, dado que eso es plenamente conocido. Más sensibilizados y con más e ineludible conocimiento, difícilmente podemos inhibirnos de las responsabilidades y las demandas éticas que a todos nos apelan para promover un mundo más humano y unas sociedades más libres, responsables y justas.

b) Los métodos pedagógicos válidos para aprender los hábitos que eduquen para ser personas válidas en el contexto anteriormente definido. $\mathrm{O}$ los ya reconocidos y bien acuñados de la educación popular, la animación sociocultural y el desarrollo comunitario, por ejemplo, u otras propuestas alternativas más difusas y emergentes que proponen fórmulas educativas innovadoras. Pero, es evidente que lo educacional tiene que mirar hacia otro lado y proponer respuestas a los nuevos interrogantes y exigencias. Mantenernos en la rutina y, eso sí, innovar sólo desde el incremento de las aportaciones tecnológicas no es promover espíritus nuevos para atender a los retos señalados. El cambio tiene que ser más auténtico, más profundo. Es más nueva la cultura actual y sus problemas y oportunidades que la acción educativa que se promueve. Y eso, en gran medida, es así porque aún no hemos decidido cómo "ser siendo humanos", qué decía Aristóteles en la Ética a Nicómaco, ni nos hemos respondido a la pregunta de Rorty $(2000,45)$, «en qué humano estoy dispuesto a convertirme?».

c) La percepción de la persona humana que se educa para ser capaz de vivir valiosamente en ese nuevo ámbito de convivencia: el yo definido más por la finalidad, el enfoque valioso de la vida, lo ético, y menos por la funcionalidad, dedicarse al desarrollo del conocimiento, de lo cognitivo, por ejemplo.

El siguiente esquema de los tres componentes, que demandan la clarificación del discurso y la acción pedagógicos, aglutina los puntos referidos: 
CuAdro 1. Componentes Implicados EN LA PROYECCIÓN PEDAGÓGICA

\begin{tabular}{|l|l|}
\hline a) Ámbito de la realidad sociocultural & $\begin{array}{l}\text { Nuevas exigencias ecológicas, } \\
\text { interculturales, convivenciales... }\end{array}$ \\
\hline b) Métodos pedagógicos válidos & $\begin{array}{l}\text { Educación popular, animación sociocultural, desarrollo } \\
\text { comunitario y otras propuestas emergentes e innovadoras }\end{array}$ \\
\hline c) Percepción del yo que se educa & Más ético que cognitivo \\
\hline
\end{tabular}

De estos tres elementos, el a) y el b) son las variables con que nos encontramos: a) el mundo establecido y los retos referidos. El punto de partida históricosocial desde el que se nos exige una nueva proyección y desarrollo educativos; b) es una de las respuestas pedagógicas más avaladas y comprometidas por una educación capaz de preparar a las personas para las nuevas respuestas cognitivas, afectivas y éticas exigidas. El componente c) es la variable de la que depende que efectivamente el elemento b) de las respuestas pedagógicas sea válido para responder a los retos reconocidos en a). Es la exigencia de replantearnos un nuevo paradigma de lo humano, una nueva forma de comprendernos como personas, que efectivamente haga viable una alternativa educacional a los retos y los problemas de nuestra sociocultura. Es el reto a investigar hoy por la Teoría de la Educación: qué tipo de yo seamos capaces de proponer y de actuar para que la convivencia en el mundo sea más viable.

Antes de seguir, conviene una mínima parada en las tres mediaciones pedagógicas referidas, propuestas como actuaciones capaces de responder educativamente a los retos y problemas de nuestra actualidad. La metodología de la educación popular (EP), debida principalmente a la acción educativa de P. Freire $(1973,1979$, 1990) en Brasil y Chile. Educación Popular que se propone como un proceso de comunicación en el que están presentes y son atendidas las palabras del pueblo. Educarse es dejar de vivir en la inconsciencia impuesta por la extensión de los lenguajes poderosos, que nos oprimen en el mantenimiento de las ideas y las creencias que se difunden sobre los "bancos" escolares. Por eso, el más decisivo valor de la educación ha de ser potenciar y elevar la conciencia, esto es, llegar a concientizarse. Concientización, neologismo con el que el pedagogo brasileño quería llamar la atención sobre la clave relevante de su pedagogía. La metodología de la animación (AS-C), como proceso educacional, añade a lo cultural conciencia crítica y reflexiva de perfeccionamiento. La animación sociocultural se caracteriza por ser un medio de promoción de valores, un elemento transformador, un cauce de participación, un promotor de la vida asociativa y un desarrollo de la comunidad. El proceso activo de la animación se realiza en las siguientes fases: toma de conciencia, consideración de alternativas, decisión, acción y evaluación. De manera complementaria, la metodología del desarrollo comunitario (DC) pretende la mejora de la vida de la comunidad, desde la propia participación activa y desde la iniciativa de la propia comunidad (en lo posible). Los postulados del DC son que es un proceso global, estructurado y participativo y que se realiza desde el apoyo de los poderes públicos. 
Tanto la EP, la AS-C como el DC, y otras propuestas innovadoras emergentes, como mediaciones pedagógicas, validadas para el logro de ciertos horizontes educativos, requieren que nos replanteemos quién es el actor humano que ha de promover esos estilos psicoculturales. Esas metodologías son propuestas de nuevos logros educativos. Además requieren plantearse, de alguna manera, desde un estilo mental, afectivo y ético, en que de forma dialéctica reconozcan cognitiva y éticamente lo que quieren conseguir y actúen hacia una mayor profundización y logro de aquello proyectado. En definitiva, es un reto de renovación pedagógica que exige retrotraernos a las fuentes de la comprensión y la aceptación de cómo sea el ser humano que actúa y se educa. Sin este repaso por el denominable "postulado antropológico", asunto clave de toda Teoría de la Educación, el discurso y la acción pedagógicos renovadores pueden quedar faltos de fundamento y de fuerza para justificar los planteamientos y el cambio. Ésa es la razón motivadora de la reflexión de estas páginas.

Interrogados desde la Teoría de la Educación, teniendo en cuenta la experiencia cultural, los sujetos educables y los proyectos valorativos ineludibles, nos acercamos a la cuestión filosófica siempre presente en la raíz de los planteamientos educacionales. Esta ineludible referencia filosófica tiene que ver con la más originaria pregunta de toda propuesta y proceso educativo: ¿quién se educa?, ¿qué visión se tiene del ser humano educable? Estos interrogantes son los que aún se mantienen, en muchos casos, respondidos desde la dominante mentalidad grecooccidental presente en siglos y siglos de historia de modernidad. La concepción del humano como substancia racional capaz de conocer la verdad y generar tecnología, regulado todo ello por el postulado dominador del progreso. Esto es lo que ya es crisis de incompetencia y de falta de adecuación en relación con los retos actuales (Touraine, 2005). En estas páginas, en consonancia con los conocimientos de hoy y las nuevas exigencias, se ensaya una renovada respuesta filosófica para replantear el cómo emprender otras teorías de la educación.

\section{La SOSPECHA DE QUE LO CONOCIDO Y ESTABLECIDO NO VALÍA}

Los cien años del siglo XIX, tras la Ilustración, la revolución política francesa (1789, Declaración Universal de los Derechos del Hombre y del Ciudadano, Libertad, Igualdad y Fraternidad) y la revolución industrial son una inagotada y permanente incidencia de revisión de las ideas y los logros alcanzados con anterioridad. Todo el flujo de acontecimientos puede ser comprendido como una secuencia de destronamiento. De puesta en "sospecha" de la imperfección y de la no plenitud de la racionalidad/conciencia, del difundido conocimiento de la verdad y del trono simbólico de la diosa razón ${ }^{1}$. Creencias y vivencias que se concentraban en la

1. Este asunto de la diosa razón es mantel prolijo en debates. Desde luego, son superables y olvidables la presencia y los efectos de la diosa razón, como el único y el más profundo sentido de la 
experiencia cultural del deísmo. El ser humano deificado en el encuentro racional con Dios, por medio de las matemáticas, paradigma y método de todo conocimiento que pretendiese reconocerse como perfecto: "Dios ha escrito la naturaleza en lenguaje matemático" (Galileo, 1981, 139). Dios entendido como una mente infinita con la que el hombre conectaba a través de las matemáticas, logro magnífico de la diosa razón. La palabra de Dios es el universo y la naturaleza. Autores ingleses, franceses y norteamericanos de los siglos XVII y XVIII (Th. Hobbes, J. Locke, D. Hume, J. J. Rousseau, Voltaire, B. Franklin, Th. Paine, entre otros) son los más significativos animadores de ese mundo de ideas y de creencias. Esta razón absoluta y objetiva llegó a ser entronizada como diosa en la cumbre entusiasta del fervor revolucionario, antes de empezar a vivirse la conciencia de malestar derivada de los desmanes del mismo afán revolucionario. Así, como muestra de aquella pasión demoledora, Robespierre abolió el culto católico y convirtió Nôtre Dame en el templo de una nueva deidad, la razón. Un buen ejemplo de cómo la razón, creída como absoluta, objetiva y universal, emana monstruos, que desde la propia exageración de poder, termina por provocar lo contrario de lo pretendido. La razón y la verdad que no rien (Eco, 1985) y que en tantos momentos de la historia han sido el trasfondo generador de tanta destrucción humana. Ciertamente, había que "Sospechar". De esa sospecha tenía que nacer, es lo que se pretende cuando se habla del humanismo, una propuesta alternativa de cómo comprender y valorar la experiencia humana.

K. Marx representa el crítico de la razón luminosa y aislada, que desde su poder clarificador es capaz de dar razón de la historia, de las experiencias y las decisiones humanas. La razón humana es tan divina, está tan a priori dotada de categorías y de métodos aseguradores de su quehacer, que no hay posibilidad de que sea manipulada, dominada. La historia de Occidente ha pretendido ser, hasta ese momento de su realización histórica, la presencia en el teatro de la vida de la sentencia de Protágoras (2005, 20), sofista racionalista: "El hombre es la medida de todas las cosas, de las que son en cuanto que son, de las que no son en cuanto que no son". El hombre, medida. Medida por medio de su poderosa razón. Ya, en cuanto que dicha diosa, y ya, en cuanto que referida como capaz de conocer el lenguaje matemático con el que Dios había escrito la naturaleza. El hachazo de Marx a esta creencia fue tremendo. Mostrar que la razón no es una abstracta y quintaesenciada posibilidad de lectura y comprensión de la realidad.

\footnotetext{
existencia. En nombre de los tres grandes valores revolucionarios hubo muerte, violencia y aniquilación sin límites. Sí la Diosa Razón entendida como la llamada kantiana a la ilustración del "atreverse a pensar" y "Salir de la minoría de edad". Sí la diosa razón de la crítica, del diálogo, de la búsqueda infatigable de la verdad, de la apertura al mundo. En definitiva, como se intuye en la canción del Grupo "Barón Rojo", Diosa Razón, cargada de eticidad, esto es, de la presencia viva y aceptada de los otros, aunque no sean de nuestra particular verdad: "Guíanos los pasos, danos la mano diosa razón, vuelve a nosotros, ábrenos los ojos, diosa razón".
} 
Que la conciencia es una forma de hablar y de referir el mundo, sus exigencias y sus condiciones. Conciencia y mundo, dos experiencias complementarias y en permanente proceso de realización. La conciencia es un mundo de referencias de sentido y de comprensión que se concreta y ejecuta en conversación con las exigencias experimentadas de la vida cotidiana. La razón no es un mundo aparte, abstracto, a priori, universal, ni absoluto. La conciencia es un lenguaje en el que representamos formas diferentes de ver y vivir el mundo. De humanos deístas y poderosos pasamos a vernos como humanos cercados por los datos de la existencia de los que no podemos abstraernos. Están y nos provocan. La conciencia es una forma de releer el mundo que nos rodea y nos acucia.

Así, Marx, en su muy famosa y citada obra,Tesis sobre Feuerbach, en la p. 11 escribe: "Los filósofos no han hecho más que interpretar de diversos modos el mundo, pero de lo que se trata es de transformarlo". Lo curioso, aceptada la crítica marxiana al uso de la racionalidad, que analiza, es que para transformar el mundo lo más originario que se requiere es una interpretación. Transformar el mundo, desde donde venimos, nuestro mundo concreto, requiere mirarlo de otra manera. Esto es, no captarlo como algo que se representa, especula, en una racionalidad matemática, de pretendida captación de la verdad de lo real. Transformar el mundo requiere que nos veamos en el mundo como un esfuerzo ético por no volcar la interpretación de la realidad hacia los intereses de quienes poderosos nos creemos dotados y capaces de reflejar lo real. La existencia es para otra cosa. No para creernos conocedores de la verdad de una realidad, que siempre oculta intereses, motivos, afanes, de quienes tienen el poder de ejecutar tales experiencias.

Marx y Engels en La ideología alemana dejaba este asunto de la razón implicada decididamente sentenciado al poder condicionante del "modo de producción de la vida material (que) condiciona el proceso de la vida social, política e intelectual en general" $(1972,67)$. Y, a continuación, la famosa sentencia muy divulgada y reconocida: "No es la conciencia de los hombres la que determina la realidad, por el contrario, la realidad social es la que determina su conciencia" (1972, 67). En el comienzo de la primera parte de La ideología alemana, dedicada a Feuerbach, K. Marx y F. Engels resumen lapidariamente su intento, que, a su vez, es el detonante global de la historia de Occidente en los dos últimos siglos. Ahí es donde se plantea la problemática de quién es el yo y de qué tipo de modernidad vale para proponer alternativas valiosas a los complicados retos de nuestro tiempo. Recuerdan Marx y Engels que en tres años, de 1842 a 1845, hubo más cambios en Alemania que en tres siglos (siglos de la presencia y el mantenimiento de la representación de la identidad moderna). Y que además ocurrió el cambio más relevante sucedido en las cuestiones del pensamiento: "Se trata de un suceso lleno de interés: el proceso de descomposición del espíritu absoluto" (1970, 5). Un rotundo resumen de la modernidad/ilustración que configura la historia y la vida de Europa durante más de 23 siglos (Sócrates-Kant). Hoy somos hijos dubitativos, pasada la modernidad, y todos en crisis. Por ello, estamos necesitados de redefinición a través de los pasos sucesivos, y de que nos reconstruyamos desde esa "descomposición del 
JOSÉ ÁNGEL LÓPEZ HERRERÍAS

¿QUÉ “YO” ES VALIOSO PARA EL MUNDO DE HOY?

espíritu absoluto". La pregunta hoy es: ¿con qué pensamiento redefinirnos, cómo desvelarnos la presencia de nuestro espíritu? ¿Cómo definirnos y reconocernos como humanos?

S. Freud es otro de los grandes desmitificadores de la razón humana. La racionalidad no sólo se creía y vivía poderosa ("la razón de la Leyenda", Kitcher, 1993) para la captación de las claves explicativas y comprensivas de la realidad. También se reconocía poderosa y transparente en la comprensión de sí misma. Lo que era razón hacia el exterior para conocer, era conciencia hacia el interior, para reconocerse como persona individual. La tradición racionalista occidental, en este caso a través de Descartes, ya contestado por B. Pascal ( $₫ E l$ corazón tiene razones que la razón no comprende", 1983, 20), nos había mostrado una conciencia traslúcida y plena de la interioridad personal. El médico vienés, en el tiempo de las "sospechas" reconstructoras, nos enseñó que la conciencia del yo no es plenamente clarividente. Esto es, que en el yo hay procesos activos de la conducta y de la imagen de la realidad exterior y propia, que no son patentes a la propia conciencia. En el yo hay presencia de motivos y de móviles supraconscientes, la cultura, y subconscientes, las pulsiones instintivas del ello. La conciencia, en vez de ser toda la persona, es una frágil organización de la presencia individual, constantemente amenazada por urgencias incontroladas de aspectos vitales que no tienen su origen en la conciencia. Es la magnífica enseñanza de Freud. Colocar la conciencia en su puesto de humilde realizadora, exigida de permanente autoafirmación, y conocer que nuestra vida y conducta no son plenamente transparentes ni claras.

A la luz de estos recortes de grandeza y plenitud de la razón humana, en definitiva del yo, sujeto de la historia personal y colectiva, se hace evidente la urgencia de estar siempre atentos a uno de los asuntos que parece más relevante en todo escenario humano. Esto es, preguntarse y clarificar la imagen del ser humano, sujeto de la historia, que ha de tomar responsabilidades y acciones en el complejo mundo cotidiano de los retos, de los problemas, de los diferentes momentos históricos. ¿Qué sujeto puede provocar las respuestas necesarias y adecuadas a los retos del mundo actual, ya considerados? ¿En qué humano "estamos dispuestos a convertirnos", glosando a Rorty (2000), para ser el actor valioso, que pueda representar el papel válido que el mundo actual nos reta?

El resumen filosófico de esos "sospechantes" del siglo XIX lo aporta Nietzsche. Es el filósofo sintetizador del sentido, la problemática y los riesgos de esa conciencia que ha aprendido a no verse como espíritu absoluto, metafísico, capaz de la verdad. El ¡Dios ha muerto! y la idea del superhombre, Zarathustra, son la cara y la cruz de la única moneda del humano nuevo, que poco después de poner en acción las prácticas derivadas de la ilustración/modernidad piensa que algo debe haber mal enfocado dado cuáles son los resultados, los efectos. Y enseguida promueve un proceso de racionalidad en el que se conoce precisamente otro humano. Un humano inmanente, autor de su propia experiencia/existencia, en permanentes procesos de comunicación. El Dios ontognoseológico, sustentador último del espíritu absoluto, ya no es necesario. Ha muerto. Desde ahí la vida humana consiste 
en liberarse de racionalizaciones sospechosas de engendrar límites, temores, como ocurre en las situaciones conocidas en la vida económica, política... Por eso, Nietzsche canta la tragedia griega en el recuerdo de Dionisos, rechaza el racionalismo socrático y recupera a Zarathustra creador y seguro, dedicado a la ineludible y retante realización humana.

Nietzsche es un confeso antisocrático, enemigo intelectual del racionalista ateniense, en donde el filósofo alemán cuelga el origen de todos los errores de la razón ilustrada. Nietzsche, cual años antes Goya en la pintura, con los truculentos dibujos de la serie "Monstruos de la razón", como Goethe en la creación literaria, romanticismo, reclaman la recuperación del humano más originario y, por qué no, más fiable, de la conexión inmediata con la naturaleza. Sócrates (Platón, 1985, 35), declarado ignorante radical, "Sólo sé que no sé nada", se empeña en la racionalización luminosa -apolínea- de lo real. F. Nietzsche, al contrario, toma partido decidido por otra razón que la apolínea que sea capaz de devolvernos a la "Sabiduría instintiva", compleja y trágica, la razón dionisiaca. Y es que según Nietzsche "a Sócrates le parecía que el arte trágico no había dicho nunca la verdad", y, por eso, "exigía que sus discípulos se abstuvieran rigurosamente de tomar parte en diversiones tan extrañas a la filosofía; lo logró tan bien, que el joven trágico Platón, para hacerse discípulo de Sócrates, empezó por quemar sus poemas" $(1967,78)$.

F. Nietzsche sintetiza en sus deliberaciones el afán de la cultura y las múltiples manifestaciones por salir de la "cárcel" lógica de la racionalidad metafísica. Cárcel que en el paso de los siglos nos ha trasladado al mundo de la explotación humana. Eso sí, desde los logros de la formalidad matemática y de su aplicación tecnológica. Antiilustrado de la modernidad, Nietzsche se esfuerza en la recuperación del humano completo/complejo. Anima un humano liberado de la barbarie de los efectos negativos de la razón abstracta, absoluta, objetiva y verdadera. La forma de expresar su antirracionalismo heleno no deja ninguna sombra: "Y a cada momento estalla una vez la sorda cólera condensada en el fondo de nuestro corazón contra ese pequeño pueblo arrogante, que tuvo la audacia de marcar, por eternidades, con el epíteto de "bárbaro", todo lo que no era suyo" $(1967,81)$.

Inmerso en su tiempo, Nietzsche escribe rotundo y enérgico. Su afán es recuperar un humano capaz de renovar la representación de la existencia y que permita una historia menos desgarradora. Expresa el dilema de la experiencia de Occidente, y más en concreto de Europa, a lo largo del siglo XIX: «La red del arte, ya sea bajo el nombre de religión o de ciencia, ¿rodeará el mundo con mallas cada vez más delicadas y fuertes, o está destinada a ser desgarrada en pedazos, en el torbellino de la barbarie febril y que se califica al presente de "modernidad"?" $(1967,83)$.

Éste es el diagnóstico y el reto en que de nuevo estamos y que apela radicalmente a los estudiosos de la Teoría de la Educación. ¿Decidimos nuestro humanismo con la razón "henchida" en los logros epistemológicos de la Física, la Política y 
la Economía, que ha derivado en el "torbellino de barbarie febril", "modernidad", o tomamos otro derrotero? ¿ Otro paradigma sobre lo humano capaz de acercarnos a otras experiencias? ¿Qué racionalidad puede acercarnos a la posibilidad de hacer presente el mundo de los DDHH, ahora que hemos comenzado un tiempo (siglo y milenio) que debe ser realmente nuevo? La respuesta de Nietzsche tiene componentes de interés: afirmar lo humano, reinsertarse en la naturaleza, recuperar la libre emoción artística, gozar de la creatividad... Volver al origen de la tragedia. Tomar partido por Esquilo en los debates mantenidos con Sócrates. Este nos ha traído hasta aquí. Hay que explorar otros caminos. La vida es aventura, creación, despliegue. Vivir otro aliento ético, que nos libere de la dominante "interpretación técnica del pensar" (Heidegger, 2004, 23) en la que estamos encarcelados, y nos acerque al pensar abierto al ser, que profundice la existencia en la morada espiritual, capaz de pastorear el ser, desde un más abierto lenguaje. Vivir otro aliento ético. Salir del humano, ya largo tiempo experimentado, racionalista, solipsista, jerárquico conocedor de la verdad (unos sí, dominadores, otro no, dominados), presente en el escenario de la historia occidental. Presente por haber traducido y vivido el "zoon logikon" aristotélico como "animal racional" y no como "animal que tiene la palabra». Desde la sustancia racional, individualista, capaz de conocer la verdad, fue cristalizando un mundo de actores poderosos, dominadores, fuertes. Prestos a organizar la vida de los otros desde el poder que emanaba del conocimiento establecido en las verdades racionales impuestas. Una verdad y una razón históricas que no reían de ninguna de las maneras. Al contrario, una razón y una verdad, diosas, que se establecían como poderes absolutos de la realidad pensada y establecida. ¡Cuánta muerte, destrucción, violencia y deshumanización en nombre de la razón henchida, conocedora de la verdad! Hasta hoy. Aún inciertos y dubitativos, ya sabemos y exigimos, aún poco, que la "verdad ríe", y que se puede traducir y vivir la sentencia aristotélica de otra manera: "animal palabra". Y la palabra nos "hará libres». Porque la palabra está para intercambiarla. Porque la palabra nace del entre (Buber, 1969), del diálogo, y esto sólo ocurre en el encuentro, mientras que la razón/verdad se hace más presente en la grandeza del soliloquio jerárquico y dominador.

Las consecuencias de ambos potenciales caminos de traducción están bien claras. Las de una traducción muy experimentadas y muy presentes. Ahí está nuestro mundo tecnoestructural, que nos "impone", a decir de Heidegger, la presencia de un mundo cosificado y de un humanismo cerrado en que el ser humano se reduce a la experiencia y la expresión de un objeto entre más objetos. Cosas. ¡El hombre ha muerto! Clara pérdida de todo aliento ético. Vivir en una morada deshumanizada por aniquilar todo lenguaje de disponibilidad abierta, encerrados en la oclusiva esfera de lo privado. Y alejarnos del cuidado del mundo como propuesta proyectiva de otra convivencia más comunitaria. Más libre, igual, digna y fraterna. Ya sabemos, sin embargo, dónde respirar las fuentes de otras posibles consecuencias. En reconocernos como humanos, como seres desde la palabra, desde cuya morada se nos hace presente la apertura verdadera del mundo. Se trata de fortalecer el 
aliento ético que no nos permita reconocernos como engranajes laborales de una maquinaria técnica y explotadora, de los humanos y del planeta, y sí nos aproxime a una experiencia ética en que el espíritu de lo humano resida más cerca de lo auténtico. Que somos un ser nacido del encuentro apalabrado con los otros. Aliento ético para que viva la palabra, que nos abre al ser, porque nos construye a todos con todos. Aliento ético para una permanente potencialidad ciudadana de respeto y de amor. Y no para el mantenimiento más o menos hipócrita, más o menos velado, de una convivencia en la que estén presentes las derivas de esa animalidad racional, substancial, capaz de conocer la verdad y de medir a los otros, débiles. Esto es, unas sociedades en que no dominen sólo los intercambios comerciales ni las alianzas explotadoras, amistosas o bélicas, que manifiesten el agotamiento y el sinsentido de un recorrido destructor y ya ¿agotado?

\section{De un lado, la Declaracion Universal de los Derechos Humanos (DDHH) y de OTRO, GUERRAS, HAMBRE, POBREZA E INJUSTICIA}

Conocido, aunque aún más profundizable, el mundo de los retos, hoy tenemos bastante generalizada la conciencia de que el mundo podría, debería, vivirse de otra manera. Cierto que podría ser peor. Y aún vivir envueltos en más hambre, explotación, analfabetismo y desigualdad. Aún más. Pero el desgraciado nivel alcanzado en esos índices no es pequeño. Se repiten permanentemente esos extremos de bienestar y opulencia frente a carencias y hambres. Muchos de los días del año para tomar conciencia de los problemas que nos acucian se refieren a estos asuntos (Día internacional de la "eliminación de la discriminación racial", 21 de marzo; Día internacional de la "erradicación de la pobreza", 17 de octubre; Día mundial del "medio ambiente", 5 de junio...). Reuniones y reuniones internacionales se activan para hablar de estos temas. (Ya en la década de los 90 del siglo pasado, fueron muy relevantes, entre otras: la Conferencia Mundial de "La Población y el Desarrollo", El Cairo, Egipto, 1994; la Conferencia Mundial sobre "La Mujer", Beijing, China, 1995). Hace muy poco, año 2000, la ONU proclamó los Objetivos del Milenio (ODM): que en el año 2015 se hayan alcanzado ciertos logros que reducirían de amplia manera los destrozos hechos y proclamados ${ }^{2}$.

Poco se ha logrado, en la mitad del tiempo señalado, de esos ODM. Las experiencias negativas entre los humanos quedan petrificadas en la inalterabilidad de los deseados cambios. En la cumbre del mundo de expresiones por

2. Los ODM: “1. Reducir a la mitad la pobreza extrema y el hambre. 2. Lograr la enseñanza primaria universal. 3. Potenciar el papel de la mujer y promover la igualdad entre el hombre y la mujer. 4. Reducir en $2 / 3$ partes la mortalidad de los niños menores de cinco. 5 . Reducir en 3/4 partes la mortalidad materna. 6. Reducir la propagación de enfermedades, especialmente el VIH/SIDA y el paludismo. 7. Garantizar la sostenibilidad del medio ambiente. 8. Crear una asociación mundial para el desarrollo, con objetivos en materia de asistencia, comercio y alivio de la deuda". 
vivir de otra manera, hace ya más de 50 años, en 1948, tras la Segunda Guerra Mundial, tras el Holocausto y el Genocidio, tras todos los destrozos macros y micros contra millones y millones de seres humanos, recién estrenada la "esperanza" de la Organización de Naciones Unidas, nos dictamos el artículo 1 de dicha declaración. Una maravilla. Esta declaración tenía que estar escrita en todos los frontispicios de todos los edificios públicos y privados. Y en todos los envases. "Todos los seres humanos nacen libres e iguales en dignidad y derechos y, dotados como están de razón y conciencia, deben comportarse fraternalmente los unos con los otros". No menos relevantes y sí reproducibles son estas palabras del Preámbulo: "Considerando que la libertad, la justicia y la paz en el mundo tienen por base el reconocimiento de la dignidad intrínseca y de los derechos iguales e inalienables de todos los miembros de la familia humana". ¿Y qué hacemos realmente por el avance global hacia esto? ¿Dónde hemos puesto nuestro espíritu?

La conciencia más apelante de la globalización mundial se hace presente en la vivencia de que ya no hay más tiempo para el engaño. Ni para la mentira ni la hipocresía. Hoy todos sabemos cómo se vive en todos los rincones del planeta (Stiglitz, 2002). Y todos sabemos que todos estamos relacionados con todo. Cualquier decisión al uso del poder del capital y de la razón tecnológica, efecto mariposa, repercute en otros lejanos kilómetros cuadrados. Y provoca en muchos humanos dolor y explotación. Por eso, estamos radical y, desde luego, éticamente obligados a reorientar el timón de nuestro espíritu y hacer que sea realmente posible la emergencia de otras verdades. De otras posibilidades, surgidas de entre todos, para hacernos la existencia más justa y digna. No hay que decirlo mucho más. Hay que hacerlo. No queda otra salida. Es hacia esa coherencia que posibilite la más valiosa presencia de lo humano hacia donde nuestra propia historia nos ha atraído.

Pero aunque es ético acordarse del giro ineludible que hemos de provocar en nuestra manera de hacernos historia, por las injusticias, las desigualdades y las frustraciones de millones y millones de seres humanos, no es esto el único motivo de las inquietudes vividas ni de los cambios realizables. El motivo más inicial de estos interrogantes sobre lo humano es acercarnos más plenamente a nuestra existencia. Esto es, no se trata sólo de pensar en humano porque hay unos que pueden y otros que no pueden. Unos que pueden acumular y no morirse del asco del hambre, ni del de la ignorancia, ni del de la explotación, ni del silencio impuesto y aplastante. Y que otros no pueden acumular y sí morirse del dolor, de la impotencia y del aplastamiento de vivir condenados a la suerte de todo tipo de carencias. El motivo más humano para volver hacia nosotros y pensarnos, buscando la proximidad más inicial de nuestro ser, es vivir el afán por darnos el más válido horizonte y sentido, espíritu, de nuestra existencia. Estar en el mundo de modo que desvelemos la "razón de ser" que nos acerque a una vida digna y alegre (Cobo, 2005). Una existencia en que aquí y allá las enfermedades del espíritu retrocedan porque las personas tengamos vivido el lenguaje que ofrezca ese horizonte de ser auténtico $\mathrm{y}$, por ello, grato y saludable. Puede que colectivamente vivamos, prolongada la vida y vencida en gran medida la mortalidad infantil en medio mundo, enfermos 
de cosas (de entes, ya objetos, ya imágenes, ya distracciones, ya velocidades, ya provocaciones, ya...). Casi, convertidos en un sistema reactivo, hechos cosas por el inmediato, rápido, superficial, trivial, estilo, con el que hoy, en muchos avatares de lo cotidiano, decimos y actuamos. "Desterrados del ser" o fuera "del camino que lleva a la vecindad del ser" (Heidegger, 2004, 11). Camino y vecindad que desde nuestro inicial espíritu humano no podemos plenamente abandonar dado que nos constituye en nuestro ser. Otra cosa es que en este momento histórico estemos errando, despistados entre las urgencias de lo que nos distrae, y no atendamos el peso hacia el que nos llama desde el silencio, siempre presente y activo, el daimon inicial, raíz, de lo humano. Ser cuidadores de los otros y de lo otro, del mundo, en cuanto que expresión compartida de la verdad del ser, que se nos manifiesta en el lenguaje. Lenguaje, desde el que nos abrimos al mundo y que se nos hace existencia desde el radical e ineludible encuentro iluminador de la relación con los otros. Nacemos para darnos la vida desde el entre de la palabra, cuidadora del ser. Nos hemos despistado y estamos a la búsqueda de pastores que nos aporten todos nuestros afanes. De dominio, de control, de poder. Y ni eso es el sentido de nuestra existencia, ni así podremos hacer por que crezca la verdad histórica del ser que se manifiesta. Necesitamos decidirnos a sobrenadar en otra filosofía de vida y en otra poesía. Algo cercano a la austeridad y sencillez del pastor que guarda el lenguaje, como morada del ser. Y que intuye desde lo inicial que vivir es hacer por el desvelarse de lo auténtico. Que todos somos hermanos y que toda acción contraria a eso nos llena la boca de "nauseabundos muros" (Sastre, 1976, 1988) de angustia y de kilómetros cuadrados de injusticia, indignidad y explotación insostenibles. Así expresa estas ideas anteriores, tomadas de él, Heidegger:

El lenguaje es la casa del ser. En su morada habita el hombre. Los pensadores y los poetas son los guardianes de esa morada. Su guarda consiste en llevar a cabo la manifestación del ser, en la medida en que, mediante su decir, ellos la llevan al lenguaje y allí la custodian. El pensar no se convierte en acción porque salga de él un efecto o porque pueda ser utilizado. El pensar sólo actúa en la medida en que piensa. Este actuar es, seguramente, el más simple, pero también el más elevado, porque atañe a la relación del ser con el hombre (2004, 12).

Déjeseme rescribir, como invitación para rumiarlo, unas palabras: «Los pensadores y los poetas son los guardianes de esa morada". El lenguaje, que como morada del ser, es donde habita el hombre. ¿Qué lenguaje humano estamos dispuestos a habitar? ¿Qué realidad somos capaces de hacer presente, de desvelar? ¿Qué "yo" para qué historia?

\section{4. ¿ESTÁ EN CRISIS DECADENTE EL SER HUMANO?}

Podíamos estar matándonos y no es así. Al menos, en muchos contextos. Vivimos en el planeta casi 7.000 millones de humanos y convivimos. La edad media de la vida se ha prolongado con fuerza, aunque no de igual modo en todo el mundo. 
La mortalidad infantil se ha reducido. Los discursos políticos y algunos económicos pretenden igualdad, justicia y libertad. Sin embargo, la narración de los desajustes, destrozos y conflictos es espeluznante e interminable. Hambre y analfabetismo en millones de humanos repartidos por todos los rincones de la Tierra. Continentes y países dominados y condenados por el poder y el conocimiento de otros pueblos. Todo el continente africano, excepto escasos kilómetros cuadrados, son hambre, ignorancia, enfermedades y muerte. Pero, también muchos lugares de las sociedades en desarrollo y de las fuertes económicamente almacenan millones y millones de desheredados, que están en permanente situación de conflicto y violencia. ¿Cuánta injusticia, exclusión y hambrientos de todas las hambres hay en México, en Los Ángeles, en Río de Janeiro, en São Paulo, en Bombay, en Beijing, en Bogotá... por no hacer la lista interminable? Ignorancia y explotación, de igual manera, en todos los paralelos y meridianos. Y enfermedad y analfabetismo. Males para la casa de todos, la Madre Tierra, por todos los rincones, y males para los otros, en todos los metros cuadrados. Crisis y cierta conciencia de que así no podemos seguir.

Y no podemos seguir en esa decadente historia de muerte, destrucción y violencia, por varias razones. Dos me parecen más llamativas. Una, porque hoy en el mundo, desde hace poco, comunicados, globalizados, mundializados, se sabe cómo se vive y qué ocurre en todos los huecos de ese mundo. Y sabemos que vivimos sobre el polvorín insostenible del desprecio, la injusticia y la más injustificable amoralidad. Otra, que ese reconocimiento de que todos nos sabemos en este mundo convive con el añadido de otras urgencias y exigencias. Las que se derivan de que hace años que hemos renovado y potenciado el discurso de las buenas intenciones. Occidente y el mundo, la Europa de Lenin, de Stalin, de Hitler, de la revolución industrial explotadora antes han escrito la Declaración Universal de los Derechos Humanos (10 diciembre 1948), que como síntesis concreta el mensaje en el artículo 1, menos citado de lo deseable.

Ante esa realidad disparatada, en un equilibrio inestable y más complejo, insostenible y retante que nunca, con esos lenguajes expresados, no sirve seguir en actitudes y conductas de engaño, de hipocresía y de mantenimiento... hasta que aguante, porque ya no puede resistir más. El humano hasta ahora pensado, soñado y vivido ha dado la última gota de sudor representado en lo ya antes y ahora vivido. Necesitamos soñar y vivir un nuevo ser humano. Por estar en el contexto occidental, un ejemplo cercano es el de Grecia. Si hace 25 siglos los griegos dejaron de escribirse desde el mithos y se descubrieron como seres de nous, logos y episteme, esto es, pensamiento, razón y ciencia, y ¡hasta aquí hemos llegado!, hoy tenemos que redescribirnos. Repensarnos y vivirnos de otra manera. Pensarnos en otro espíritu.

Hoy el tema más rutilante y exigible en nuestro indagar, conocer e investigar no puede ser otro que preguntarnos: ¿qué humano, qué ser, siendo humano, estoy preparado para definirme? Hoy la decadencia plena consiste en mantenernos por más tiempo en el animal racional de la tradición europea substancial y cognitiva, 
activa durante 25 siglos. La salida de la decadencia y de los tremendos retos que nos acucian exige cambiar (metáfora teatral, dinámica y expresiva), cambiar, ya, el escenario, la tramoya, el libreto, pero, sobre todo, el actor. ¿Quién soy yo y cómo me reconozco? La respuesta hoy, pasado el siglo XX, como cenit realizador de los desajustes y los destrozos de la substancia racional anterior y exigidos por los necesarios cambios, nos acerca a vernos como humanos éticos. La salida de la decadencia y el horror en que vivimos, que desde luego puede incrementarse, más agotamiento ecológico, más destrucción y muerte humanas, exigen comprender que se puede vivir humano de otra manera. Desde y en otros estilos mentales, afectivos, estéticos, éticos. Reconocernos como seres que existimos desde y para que se realice en cada caso el adecuado encuentro humanizador de unos, quienesquiera que sean, con otros, dondequiera que estén. No más animal racional, para imponer mundos, verdades, creencias, ciencias, técnicas, unos, poderosos, a otros, podidos. Sí, más humanitas ética, para que todos y cada uno tengamos la efectiva posibilidad de desvelar el ser desde la humanizante palabra de cualquiera. Esto puede provocar la salida de la decadencia y la emergencia de otro posible y válido recorrido de historia. Más humana, porque desde ahí, viviremos más libertad, más igualdad, más dignidad y más fraternidad.

\section{LA NECESIDAD DE UN NUEVO PARADIGMA}

Hace ya algunos años que entiendo que uno de los problemas claves del discurrir dominante sobre el asunto precedente está condicionado por un limitado y negativo pie forzado perceptivo. El siguiente: que estando nuestra cultura occidental dominada por el enfoque intelectualista, cognitivo, lógico, del ser humano, nos identificamos como seres vivos en cuanto que "animales lógicos", como "animales racionales" (Gil, 2001, 45-68). Más como seres que encuentran la propia identidad, en cuanto que substancias, en el carácter fundamentante de la racionalidad. Eso nos define como seres individuales, como substancias realizadas en la propia racionalidad, que posteriormente se socializan en el encuentro con los demás. Lo que el filósofo medieval Boecio definía como una expansión del sintético "animal racional" aristotélico: "rationalis naturae, individua sustancia", "una sustancia individual de naturaleza racional". Es el yo de la modernidad y de las dos derivas diferenciadas de ese yo, la postmodernidad, yo de racionalidad diluida, y la ultramodernidad, yo de racionalidad exacerbada. Lo que ocurre es que desde el enfoque de ese "yo sustancia racional", del "yo fuerte y dominador desde el conocimiento", aceptado y mantenido, toda aplicación metodológica, ya de educación popular, ya de animación sociocultural, ya de desarrollo comunitario, poco o nada puede alcanzar educativamente hacia el logro de personas y sociedades más ecológicas, más interculturales y más cooperativas. Todo ello por falta de coherencia. Lo más necesario para cambiar los estilos mentales y culturales de nuestro hoy, y para hacer eficaz y válida la "nueva pedagogía" de la educación popular, la animación sociocultural y el desarrollo comunitario, es que 
se haga más expreso el cambio hacia otra manera de considerar la percepción del humano, que se educa.

Tras la Segunda Guerra Mundial, los filósofos M. Heidegger y J. P. Sartre se dedicaron a la tarea ineludible de preguntarse quién era ese ser humano capaz de tanta barbarie. Establecieron esa metodología crítica de la "destrucción", después "deconstrucción", de los pensamientos que habían estado en el trasfondo de esas lamentables virulencias bélicas, explotadoras y violentas de unos humanos a manos de otros. La visión heideggeriana respecto de las preguntas claves, "¿cómo devolverle un sentido a la palabra humanismo?» (2004, 15), “¿en qué consiste la humanidad del hombre?", y "¿idesde dónde y cómo se determina la esencia del hombre?" (2004, 21), está transida de crítica a la técnica, a lo "impuesto". Como efecto inundante y dominador del vivir y, sobre todo, como forma en la que el pensar humano cerrado a eso "impuesto" encara los retos de la existencia. Y es que "en la interpretación técnica del pensar se rechaza al ser como elemento del pensar" (2004, 12). Eso es lo que el mismo pensador llama la "caída". "Caída" entendida como la pérdida de la "vinculación esencial del hombre con el ser inscrita dentro de la relación del ser con el ser humano" $(2004,41)$. Relación que se da en la "casa del ser, el lenguaje, y que para que se dé requiere que el hombre se entregue al "cuidado" de ese pensar inicial.

Las preguntas anteriores, formuladas por el mismo Heidegger, pueden ser respondidas al menos de dos maneras: a) desde la rechazable interpretación técnica del pensar, b) desde la aceptable interpretación abierta del pensar. La propuesta a) nos reduce y des-humaniza. Nos limita en aquello que nos constituye: que pensando en el lenguaje nos abrimos al ser, al mundo. La gran conquista de la Carta es que pretende animar y potenciar la dignidad humana. «El hombre no es sólo un ser vivo que junto a otras facultades posea también la del lenguaje. Por el contrario, el lenguaje es la casa del ser: al habitarla el hombre existe, desde el momento en que, guardando la verdad del ser, pertenece a ella" (2004, 43).

Cuadro 2. Dos paradigmas del pensamiento

\begin{tabular}{|l|l|}
\hline \multicolumn{1}{|c|}{ INTERPRETACIÓN TECNICA PENSAR } & \multicolumn{1}{|c|}{ INTERPRETACIÓN ABIERTA PENSAR } \\
\hline $\begin{array}{l}\text { Animalidad racional: racionalidad ejercida } \\
\text { sobre lo "impuesto", lo inmediato, lo cerrado. }\end{array}$ & $\begin{array}{l}\text { Humanitas ética: racionalidad } \\
\text { comprometida por y para el mundo. }\end{array}$ \\
\hline Tekné: producir efectos. & $\begin{array}{l}\text { Pensar el ser en el lenguaje, en donde se } \\
\text { manifiesta: el lenguaje, casa del ser. }\end{array}$ \\
\hline $\begin{array}{l}\text { Pensar/lenguaje: por y para lo "impuesto", } \\
\text { para lo cerrado: horizonte animal. }\end{array}$ & $\begin{array}{l}\text { Humano: "guardián" de la morada del } \\
\text { ser: horizonte de la bumanitas. }\end{array}$ \\
\hline Vivir para la presencia de lo "impuesto". & Vivir para que el ser se manifieste: lo abierto. \\
\hline $\begin{array}{l}\text { Estar en la producción, en los } \\
\text { efectos, en la técnica. }\end{array}$ & $\begin{array}{l}\text { Estar en el mundo: en la posibilidad, en la } \\
\text { apertura, en la acción para la manifestación } \\
\text { (a-lefeia) de la verdad del ser. }\end{array}$ \\
\hline Explotar entes (naturaleza, otros...). & "Cuidar" el mundo. \\
\hline
\end{tabular}


En la secuencia "deconstructora" de la filosofía alemana y francesa, Heidegger ve superable la visión técnica de lo humano, establecida de antiguo desde la animalitas del animal racional: género y diferencia específica. Esto que se propone, planteado así, parece ir contra la Lógica. Es una objeción que el mismo Heidegger se interpone: "Pensar contra "la Lógica” no quiere decir romper una lanza por lo ilógico, sino quiere decir sólo repensar el logos y su esencia, aparecida en el amanecer del pensar, quiere decir: esforzarse en primer lugar por la preparación de tal repensar" $(2004,66)$. Ese esfuerzo por el repensar es lo fundamental de la humanitas del homo humanus. Es la realización de quien se abre al ser, sabiéndose "ser en el mundo". "El hombre emerge en la apertura del ser, la cual es el ser mismo, que como arrojo se ha proyectado la esencia del hombre en el "cuidado"" $(2004,50)$.

\section{El nuevo paradigma dice QUe la finAlidad EXISTENCIAL ES REALIZARSE ÉticAmente, NO CONOCER}

La grandeza de nuestro «tiempo eje» (Jaspers, 1976), cargado de problemáticas y de exigencia de nuevas respuestas, deriva de que de manera insoslayable nos enfrenta con la necesidad de ofrecer alternativas válidas. Esto es, que son retos que nos obligan a dar respuestas auténticas y a radicalizarnos en la exigencia de acertar en lo logrado. Y esto nos lleva a replantearnos y dar como superado el tiempo del logos, que tras el mithos, se estableció en Occidente desde la revolución helénica de la racionalidad lógica y epistémica. Esa racionalidad greco-occidental, basada en el yo substancia y en la finalidad del conocimiento, como eje de la existencia, y en los efectos de la filosofía y de la ciencia natural y humana, con las derivas de la industria, la tecnología y la convivencia de pretensión democrática, no es suficiente punto de apoyo para responder y provocar el valioso estilo educativo requerido por esos retos. Hay que saber el nuevo tipo de ser humano que sea posible, que valga (valor) para esa sociocultura retante. Es la propuesta del yo metamoderno: el yo persona, basado en una nueva finalidad. No la de saberse y reconocerse como humano desde la plataforma primigenia de ser una substancia racional, sino más bien saberse humano desde la experiencia del radical encuentro ético en el que todos nos sabemos y reconocemos humanos/hermanos.

La expresión del humanismo metamoderno aparece en la prolongación del humanismo heideggeriano y sartriano. Vale el compromiso existencial de Sartre, pero queda superado el punto de apoyo de la primera verdad, buscada en el cogito cartesiano, por el desarrollo y la explicitación ontoantropológicos de Heidegger: el yo es hijo de la palabra intercambiada con los otros. Es en la palabra, que a todos nos realiza y hermana en la dignidad de hacernos humanos, en donde se nos desvela el ser. Se nos hace presente la potencial vida auténtica del ser. Véase la enorme cercanía fonética de "humano" y "hermano".

Este planteamiento del humanismo metamoderno nos acerca a una perspectiva ética de la razón (a otro peso del espíritu), que supera la anterior perspectiva 
lógico-racional. En este horizonte de la razón lógica cada yo es un pensante aislado, una sustancia, capaz de conocer la verdad y de medir lo real, a través de ese conocimiento. "Dios ha escrito la naturaleza en lenguaje matemático". Éste es el planteamiento de la modernidad del que procedemos y que se ha hecho presente en la historia: a) tomando medidas de poder en una jerarquización de poderosos y podidos, según unos consiguiesen imponer a otros la verdad; b) haciendo presente en la forma de vida el efecto dominante de esa racionalidad sustante cognitiva, la técnica y todos sus productos; y c) realizando un estilo de convivencia y de relaciones, entre todos los humanos y de éstos con la naturaleza, basado en la explotación, la competitividad y las jerarquías.

En el "tiempo eje" actual, la propuesta de la razón ética metamoderna, que atisbamos, cada yo es un existente "abierto al ser". Un alguien en el mundo, radical y originaria "respectividad" ${ }^{3}$, en cuya relacionalidad emerge la palabra dialogada, desde la que cuidamos el ser. Y desde la que, a su vez, nos hacemos seres cercanos a los dioses, a lo "insólito" (el "daimon" de la expresión de Heráclito, referida por Heidegger: "ethos anthropo daimon", "la morada para el hombre es el espíritu", 2004, 73). Nuestro espíritu es la presencia que emerge de la palabra dialogada, desde el encuentro con los otros. Sin este encuentro con los otros, otras palabras, no se concreta la realidad del espiritu de cada uno. "Somos huellas que se sintetizan en palabras", sentenciaba Vigotski (1977), como argumento psicológico de la visión inicial antropológica, que aquí se defiende, de la gramaticalidad. "El sí del presente viviente es originariamente una huella" (gramma, buella, Derrida, 1985). En este escenario de seres de palabra, cuidadores del espíritu, arrojados al mundo, la acción humana ya no viene marcada por la lógica impositiva de la verdad, que se creía alcanzar. Por el contrario, se caracteriza por dar paso a una acción humana comprendida como acción-en-el-mundo, originariamente realizada desde la emergencia de la palabra en el diálogo. Hecho que a todos nos dignifica al hacernos humanos y nos ofrece las señas de identidad desde el trasfondo de la radical igualdad de todos, en cuanto que interdependientes.

Esa reconocida racionalidad ética (metamoderna), nacida de la "morada" (ethos, con "eta", con "e" larga, que en griego significa casa, morada, estilo de vida) humana de la palabra dialogada, en la que todos cuidamos la presencia del ser (alefeia,

3. Se trata esta cuestión de la mano de ZuBiri, filosofía que nos puede aclarar la visión de la realidad derivada de la epistemología de la Física y del conjunto de saberes referidos a diferentes ámbitos de lo real. Dice el filósofo español en Inteligencia sentiente: "La realidad es formalidad abierta. Por eso la realidad es constitutivamente respectiva. En su virtud cada cosa por ser real está desde sí misma abierta a otras cosas reales. De ahí la posible conexión de unas cosas reales con otras. Que exista esta conexión es un hecho, y solamente un hecho" $(1980,196)$. Y poco después afirma: "A diferencia de lo que se pensó en inteligencia concipiente, a saber que lo real es sustancialidad y objetualidad, en inteligencia sentiente lo real es sustantividad. Por tanto, las notas no son accidentes "in-herentes" a un sujeto sustancial, ni son predicados de un objeto, sino que son momentos constitucionalmente "co-herentes", en un sistema constructo sustantivo" (1980, 207). 
verdad), es el horizonte existencial desde el que podemos acercarnos a la superación de las degradaciones anteriores, provocadas por la otra racionalidad lógica. Esta racionalidad lógica ha sido un paso de madurez en la experiencia histórica, anterior y duradera, la que nos pasó del mithos al logos. Sin embargo, este proceso recorrido no debe quedar anquilosado ni mantenido por más tiempo, como el único, como el valor. Sobre todo, porque no ayuda a narrar el estilo humano capaz de superar las deficiencias culturales reconocidas. Y que ya ha sido deconstruido en mucho pensar del siglo XX (Nietzsche, Heidegger, Derrida, Foucault). La razón ética metamoderna es la narración del yo que debemos estar dispuestos a realizar. Básicamente, por dos razones: a) es más aceptable en el conjunto de los conocimientos que hoy poseemos sobre la vida y lo humano (los conocimientos neurológicos, antropológicos, psicológicos, sociológicos, pedagógicos están más cerca de la tesis que considera lo humano como una realidad respectiva, relacional, dialógica, que no como una substancia racional y apriórica), y b) es una fórmula narrativa más coherente con los retos y las dificultades a los que nos enfrentamos, dado que (para vivir en más interculturalidad, en más respeto y cuidado de la naturaleza, con menos dominio explotador y jerárquico de unos sobre otros, en más paz y menos pobreza, en menos analfabetismo, en más justicia y libertad) se requiere otro tipo de persona. Un humano capaz de reconocerse emergido del encuentro con los otros, y no como un ser substancia, dotado de más poder de conocimiento y de verdad que otros, de entre los que, desde luego, no se siente emergido.

¿Qué es el hombre? La cuarta pregunta de Kant brota ahora como un rugido desgarrado. Un ahora lastrado de hambre, pobreza, explotación, belicismo y fronteras. Un ahora teñido de miedos, inseguridades y violencias permanentes, más o menos tácitas o expresas. Además de las truculencias ocurridas, y por ¿ocurrir?, nos hemos quedado sin fundamentos. Ya diluidos en la sinrazón del postmodernismo de una cognición desengañada (Bauman, 2007). Ya exacerbados en el deterioro agresivo de la ultramodernidad de una cognición radicalizada. Sin Dios y sin razón. Sin el Dios ni la razón de la modernidad, casi identificados, la diosa razón, que habían parecido las referencias válidas para significar el progreso de la historia humana. ¿Qué es el hombre? ¿Dónde está el espíritu? ¿Dónde encontrar el fundamento y el sentido de vivir para hacernos el bien? ¿En qué basar el humanismo: los derechos humanos, "la libertad, la dignidad, la igualdad, la fraternidad"? Se requieren nuevos horizontes, otros valores. Otra visión del ser humano. Un nuevo actor para narrar otra forma de vivir. Válido para este mundo globalizado. En el que haya menos acciones culturales teñidas de violencia, venganza y desprecio.

Los tiempos nos exigen otra respuesta de profundización humanista. De estar en la sensibilidad de Heidegger y de Sartre, incentivados y requeridos por las experiencias europeas y mundiales que se vivían en las décadas del siglo XX. Y desde ahí indagar y proponer otros animosos horizontes de valor para hacer posible la convivencia humana en la Madre Tierra. Venimos de varios y acumulados desengaños históricos. Sin aclarar el porqué del contrato social que nos permita vivir juntos. Con fuerza, de nuevo, más hombre lobo para el hombre. Necesitamos 
un nuevo fundamento para otro contrato social en el que sea imaginable narrarnos como seres con más "libertad, dignidad, igualdad y fraternidad". Y menos mantenernos en este contrato en el que la violencia, la explotación, la lucha y las secuelas del hambre, la guerra y la pobreza sean tan generalizadas y truculentas.

\subsection{Distinguir función y finalidad}

Para respondernos a las preguntas y a las inquietudes anteriores es relevante no confundir función y finalidad. Por ejemplo, los humanos por el hecho de tener piernas no hemos nacido para andar. Con las piernas activamos la función motórica, pero no hemos nacido para caminar, como fin. Los seres humanos conocemos, pero no hemos nacido, finalidad, para conocer. Esto es una función de nuestra existencia. Nuestro fin es vivir, y la vida de cada uno, realizadora de muchas funciones, se hace presente en y desde un radical encuentro con los otros. Los humanos nos abrimos al ser, al mundo, desde el originario intercambio del don de la palabra. La finalidad de nuestra existencia es hacernos unos a otros la convivencia, la realización personal de la existencia, vital y valiosa. Para ese fin deben actuar todos los elementos funcionales de nuestra compleja realidad humana. Entre ellos, el conocer. Hoy podemos saber, tras la historia cognitiva recorrida, que somos para encontrarnos de forma humanizante: aquella que reconoce que el sentido más radical del ex - sistir consiste en "darnos (la) vida" (de seres humanos) unos a otros. Por eso, Heidegger resume el valor y la radicalidad de la ética, en esta bella sentencia: "Las tragedias de Sófocles encierran en su decir el ethos de modo más inicial que las lecciones sobre "ética" de Aristóteles" $(2004,75)$.

\section{CuAdro 3. Diferencia ENTRE FinAlidad y funCión}

\begin{tabular}{|c|c|}
\hline Finalidad & Funciones (medios) \\
\hline $\begin{array}{c}\text { Criterio dilucidador: aquello que es la fuente originaria } \\
\text { de la persona de cada uno: el encuentro respectivo } \\
\text { dialogante (el humano, ser [de] palabra). }\end{array}$ & $\begin{array}{c}\text { Criterio dilucidador: todas aquellas } \\
\text { acciones de la complejidad } \\
\text { humana (bio-psico-socio- } \\
\text { cultural) que posibilitan la } \\
\text { concreta realización personal. }\end{array}$ \\
\hline $\begin{array}{c}\text { Que la ineludible presencia interhumana, nos } \\
\text { hacemos unos con otros, no realice de la manera } \\
\text { más válida para la emergencia de cada persona, } \\
\text { "yo", en el necesario encuentro "nostral". }\end{array}$ & $\begin{array}{c}\text { alimentarnos; andamos (tenemos } \\
\text { piernas), no hemos nacido } \\
\text { para caminar. Conocimiento } \\
\text { (tenemos capacidad cognitiva), } \\
\text { no hemos nacido para conocer. }\end{array}$ \\
\hline
\end{tabular}

Desde este planteamiento, la modernidad racionalista y sus secuelas, postmoderna y ultramoderna, han agotado su proyección humanizadora, y deben ser re- 
emplazadas. Esto es, completar la función de la racionalidad en el proyecto de un nivel más auténtico de finalidad humanizante. Que la vida humana se manifieste y desarrolle desde el daimon, desde el espíritu, desde la ética. Comprender que hacerse humano no es una expresión de la funcionalidad cognitiva, sino una manifestación comprometida de cómo hacernos personas con los otros.

Estando la funcionalidad, conocer, entre otras, al servicio de la finalidad, realización compartida con todo otro, las personas no son objetos funcionales de las finalidades cognitivas establecidas. Las personas dejan de ser medios para fines prefijados. Para los fines impuestos por los conocedores poderosos, que desde su verdad tomaban y ejecutan medidas a la realidad. Ahora, las personas, el otro y yo, cada uno, pasamos a ser la exigencia ética de nuestro valor en el mundo, como existentes. Todo otro aspecto de la compleja realidad humana pasa a ser algo que funcionalmente debe estar al servicio de la finalidad descubierta y reconocida. La existencia como una propuesta de compromiso ético es el ámbito de realización de los encuentros humanos. A este objetivo, a esta finalidad, quedan supeditados el desarrollo y el logro de cualquier otra actividad humana. También la de conocer para reflejar la realidad, que siempre era la que se imponía.

\section{CuAdro 4. Tipología de la identidad personal}

\begin{tabular}{|c|c|}
\hline \multicolumn{2}{|c|}{ Paradigmas comprensivos y valorativos de lo humano } \\
\hline $\begin{array}{c}\text { Paradigma antropocognitivo } \\
\text { (funcional: durante siglos se ha }\end{array}$ & $\begin{array}{c}\text { Paradigma antropo-ético (se descubre } \\
\text { entendido como finalidad; confusión } \\
\text { entre la función y la finalidad). }\end{array}$ \\
y acepta que una función, por muy relevante \\
YO MODERNO: substancia cognitiva, & que aparezca, no es la finalidad). \\
capaz de conocer la verdad: (crisis) & YO METAMODERNO: respectividad ética: \\
YO POSTMODERNO: substancia & racionalidad ética, que integra y supera \\
cognitiva diluida. & (metá-) la racionalidad lógica anterior. \\
YO ULTRAMODERNO: & Occidente: tres palabras comprensivas del \\
substancia cognitiva exacerbada. & "desvelamiento" de lo real: de la mítica \\
& a la lógica, después, a la ética: \\
\end{tabular}

No hemos nacido para conocer y con palabras de poder, derivadas de ese conocimiento, jerarquizar, dominar y explotar. Existimos como yo en cuanto que intercambiamos palabras, que nos posibilitan participar en el cuidado del mundo, comprometiéndonos a vivir de modo que todo y cualquier ser humano (toda realidad) tenga la presencia y el vigor de su palabra. Los humanos hemos nacido para ser hermanos. Somos humanos en cuanto que nos hermanamos en las palabras que intercambiamos y nos hacen. El conocimiento que de ahí se deriva no debe ser, convertido falazmente en sustancia cognitiva, un medio para deshumanizar la existencia. Seguir en un potencial desvelamiento de humanidad requiere decidir vivir desde otro guión narrativo. Que no somos substancias de diferente potencialidad de poder, desde el conocimiento dominador. Que más bien somos seres de 
radical interdependencia, emergidos del encuentro con los otros, dado que todos somos presencia de intercambio de la palabra participada y comunicada, que nos realiza, en cuanto que humanos/hermanos existentes. Éste es el punto de partida y de llegada de las metodologías pedagógicas de la educación, de la animación sociocultural y del desarrollo comunitario, mediaciones educativas que actúan desde el horizonte valorativo de un ser humano, que sea capaz de responder a los retos y los conflictos de nuestro complejo mundo actual.

\subsection{Algunas notas para el libreto educativo del nuevo actor psicocultural}

Una Teoría de la Educación:

- Que apoye el valor de la palabra de cada uno: superación de los invisibles y de los discursos dominantes, de modo que toda potencial palabra esté presente para el diálogo superador.

- Que promueva la emergencia holística de la persona: la afirmación total de la complejidad personal, siendo reales los sentidos afectivos, estéticos, éticos, además de los eminentemente intelectivos.

- Que eduque para la apertura de la disponibilidad y no para la cerrazón de lo seguro: de modo que la existencia se viva como un permanente desarrollo de nuevas y creativas posibilidades de verdad, belleza y bondad, y no como el rutinario mantenimiento de lo establecido.

- Que divulgue, anime y experimente la conciencia del yo, como realidad participada y no como originariedad substancial: un nuevo actor narrativo más capaz de generar otros estilos de sociedad y cultura para la paz, la justicia y la deseable fraternidad.

- Que actúe para potenciar personas animadas para la competencia cooperativa (la co-competencia), y no para la competencia competitiva (competitividad) jerárquica y dominadora: dado que no debe ser finalidad de los grupos humanos explotar la tierra y a los grupos desheredados, hasta que la propia presencia sea insostenible desde todos los puntos de análisis.

\section{CONCLusión ABIERTA}

El discurso ha considerado tres ángulos interdependientes: a) los desafíos de nuestra cultura actual, tecnológica, globalizada y comunicada, ante los que ha crecido la conciencia de que se hacen necesarias otras respuestas y formas de vida que sean alternativas de las establecidas y dominantes; haciendo posible, además, que progrese la presencia y expresión en nuestras sociedades de los derechos universales; b) el afán innovador de los teóricos y los prácticos de la pedagogía siempre animados para proponer otras finalidades y mediaciones 
educativas, que nos preparen de forma adecuada para solventar con éxito los nuevos retos culturales referidos; el diagnóstico global es que somos ejes psicoculturales antiguos, poco preparados para afrontar con éxito las demandas de la sociocultura actual; y c) el aspecto analizado en este trabajo: qué tipo de identidad, de "yo", qué actor narrativo requiere nuestro mundo actual para que sea factible representar en los renovados escenarios de nuestros contextos ese tipo de existencia humana, de "ser siendo humano", que dé soluciones valiosas a los conflictos, retos y situaciones nuevas de nuestro hoy.

El análisis se ha centrado en el conocimiento del sujeto, capaz de dirigirse hacia los nuevos valores de nuestro mundo: más interculturalidad, otro grado de justicia y dignidad, otras concreciones de la libertad y de la conciencia cívica, otra atención a la naturaleza y a los otros, un más profundo respeto por el sentido de una vida participada, comprometida y en paz. No el sujeto de la tradición moderna, ni sus dos dominantes aplicaciones críticas, el postmoderno y el ultramoderno. Básicamente porque son sujetos dotados para la representación, definidos desde la sustante individualidad, de tendencia egotista. Este sujeto no puede ser el actor de la igualdad, ni de la solidaridad. Ni de los otros valores y derechos propuestos. La alternativa desarrollada es la del sujeto metamoderno: una identidad personal que se reconoce en el encuentro ético con los otros.

El análisis más operativo se refiere al proyecto educativo de los centros escolares. Falta deconstruir más nuestra escuela y, desde luego, proponer con más compromiso ético qué escuela vale para alcanzar personas y comunidades, como las que se advierten tras listados valorativos como el aquí estudiado. La escuela del individualismo burocrático-político, dominada por el actor individuo, que aprende para su propio beneficio, y consigue clasificar a las personas/alumnos en categorías jerárquicas de diferencias insalvables no parece el lugar adecuado. Depende de para qué. Desde luego, no para el qué de los valores de más solidaridad, igualdad, interculturalidad, libertad y fraternidad que el mundo requiere. El reto de la mejora humana sigue lanzado. Nos queda hablar y pasar a la acción, desde lo hablado. Renovar las palabras desde y con las cuales situarnos en el mundo es una tarea ineludible y crucial. Hacia un nuevo presente y futuro hay una inundante exigencia de hacernos con un nuevo sujeto histórico y personal. Una educación con mayor capacidad de respuesta ética (Vila, 2005). Ésta es una de las más relevantes y significativas tareas de la Filosofía y Teoría de la Educación en el momento actual. Considerar que la verdad, el conocimiento, la ciencia y la tecnología son valores y aplicaciones positivas de la existencia humana. Pero que todo eso debe quedar regulado por el conocimiento ya hoy adquirido sobre lo humano: que somos y existimos para la finalidad de la ética interhumana que nos hace. Todo lo otro ha de quedar supeditado, establecido, regulado al servicio del buen hacerse de esa ineludible finalidad: que somos todos interdependientes de todos y que nos hacemos en el "entre" (Buber, 1969) de la radical interdependencia conversacional. 
JOSÉ ÁNGEL LÓPEZ HERRERÍAS

¿QUÉ "YO" ES VALIOSO PARA EL MUNDO DE HOY?

\section{REFERENCIAS BIBLIOGRÁFICAS}

Aristóteles (1951) La Política. Madrid, Instituto de Estudios Políticos.

Bauman, Z. (2007) Miedo líquido. La sociedad contemporánea y sus temores. Barcelona, Paidós. Buber, M. (1969) ¿Qué es el hombre? México, FCE.

Сово, J. M. (2005) Otro mundo es posible. Propuesta de una utopía para el siglo XXI. Madrid, Biblioteca Nueva.

DerRIDA, J. (1985) La voz y el fenómeno. Valencia, Pre-textos.

Eco, U. (1985) El nombre de la rosa. Barcelona, Lumen.

FreIre, P. (1973) Pedagogía del oprimido. México, Siglo XXI.

- (1979) Educación y acción cultural. Bilbao, ZERO.

- (1990) Naturaleza política de la educación: cultura, poder y liberación. Madrid, Paidós, MEC.

Galilei, G. (1981) El ensayador. Buenos Aires, Aguilar.

GIL, F. (2001) Educación y crisis del sujeto. Teoría de la Educación, 13, 45-68.

Heidegger, M. (2004) Carta sobre el humanismo. Madrid, Alianza Editorial.

JASPERS, K. (1976) Origen y meta de la historia. Madrid, Revista de Occidente.

Kitcher, Ph. (1993) The advancement of science. N. Cork, Oxford University Press.

Marx, K. y Engels, F. (1972) La ideología alemana. Barcelona, Grijalbo.

Nietzsche, F. (1967) Obras Completas (V) El origen de la tragedia. Madrid, Aguilar.

- (1996) Humano, demasiado bumano (2 tomos). Madrid, Akal.

Pascal, B. (1983) Los pensamientos. Madrid, Alfaguara.

Platón (1985) Apología de Sócrates. Madrid, Gredos.

Protágoras (2005) Protágoras/Platón. Madrid, CSIC.

RoRTy, R. (2000) Verdad y progreso. Barcelona, Paidós.

SARTre, J. P. (1976) La náusea. Barcelona, Proa.

- (1988) El muro. Madrid, Alianza.

- (1996) El humanismo es un existencialismo. Madrid, Santillana.

Stiglitz, J. (2002) El malestar de la globalización. Madrid, Taurus.

Touraine, A. (2005) Un nuevo paradigma: para comprender el mundo de hoy. Barcelona, Paidós.

Vigotski, L. S. (1977) Pensamiento y lenguaje. Buenos Aires, La Pléyade.

VILA, E. (2005) Mundo de la vida y cultura: la educación como acción ética e intercultural. Teoría de la Educación, 17, 81-96.

Zubiri, X. (1980) Inteligencia sentiente. Madrid, Alianza Editorial. 